\title{
Passing by on the other side
}

W hich one of us, seeing the distress of a fellow human being, could avert his eyes and pass by as if seeing nothing? None of us - particularly now that the world is a global village. Television and instant news reporting have changed everything. Plastic surgeons have always volunteered their services around the world in times of crisis. This has led to a bank of understanding in our speciality. Here are a few ideas:

1. Modern anaesthesia has made it simple and safe to perform extensive surgery in crisis situations. Lives can be changed by relatively simple procedures such as skin grafting and cleft lip repair. Surgery is best performed in teams and there must be local support for projects like these. Teaching is an important goal. Treatment programs should be time limited. You must have a leaving date before an arrival date. It is only fair for the local people that no one should become dependent on a project. Bitter feelings happen when aid is too suddenly withdrawn.

2. Any surgeon or nurse who works abroad will learn far more than they teach. This is not merely advice for the proper attitude to have, it is true. In the west we have many beliefs which, if examined, are not true. The most insidious is that what we do is best and should be emulated around the world. In short, this arrogance gets in the way. We sometimes think local surgeons are not as capable as we are. Try operating with them and you will find otherwise. You will find modest, courteous, friendly and tremendously experienced surgeons who have far wider experiences than the visiting surgeons who help them. The irony of this is not appreciated by those of us who wear blinkers. Take the blinkers off and look around. Pitch in, learn and enjoy the situation. You quickly learn that surgeons, nurses and patients are the same around the world. You are now working in the global operating room, part of the global village.
3. You have travelled to another country to assist where you can. You find the need is not so much for your skills but for all the medication and equipment you take for granted at home, and you ask yourself why they don't have what is necessary to do surgery? It dawns on you that it takes

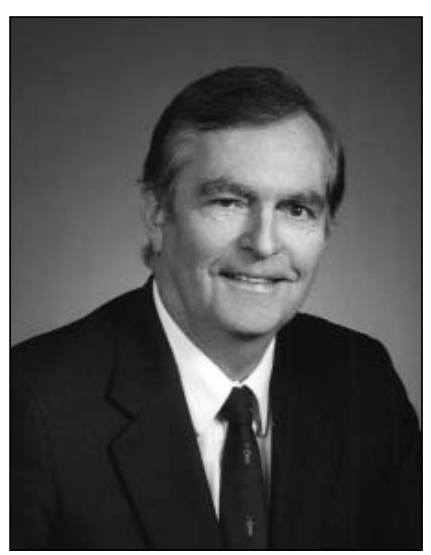

John R Taylor two things: an economy with money to spend on surgery and a willingness to spend it. You are innately proud of your 'can-do' attitude and you dislike the 'what can you do?' attitude. You now perceive your attitude and culture as a secret of success and wonder if you could teach it by words or example. This is an essential coping mechanism you detect in yourself as well, so you become more tolerant. Your 'can-do' attitude is seen in its true light. When you need something, you demand or convince someone to give it to you, but your situation is now different. There is nobody local who has it, so you can't demand it. You think you can do more with less because of your ability to cope, but you find the local surgeons cope much better with far less.

4. You begin to see your culture as someone else would see it and although you are proud of it, you know the people you are visiting are just as proud of their own culture - in a modest way. It is a shock when you start to see your own culture from the view of your guests, and see how much we consume with so little effect. While abroad, you meet many people who have lived in your culture and know it more 
intimately than you know their culture. You start admiring their way of doing things and realize this must be what the imperialists called 'going native', but maybe it is just appreciating people.

5. You see that there is a difference between aid and development. Aid is a direct service; development is far more complex, involving long-term planning and the decision as to what is best left to the professionals. Poorly planned development has the insidious downside of suppressing local initiative.

The following are true stories:

A surgical visitor to Java worked in a large hospital in the 1970s for two weeks, where comparatively few operations were performed. The visitor thought the problem was due to the type of anaesthesia used - ether. Ether took a long time to induce, so few operations were performed despite the unbelievable need. The local surgeons were honestly amused that the visiting surgeon thought that seeing a few extra cases would make a difference, considering they were experts in treating without surgery things the visitor was used to operating on. The visiting surgeon suggested that local anaesthesia be used. In the entire hospital there was only one large ampoule of procaine, and no lidocaine. The visiting surgeon said, "use the procaine, then it will have to be replaced." The local surgeons said, "if we use it, there will be none to use." The visitor said, "you are using none now; try it, you will like it and get more."

The procaine was not opened. Who was right? Was anyone right?

A Swiss technical teacher commented on the above story. He said, "the problem is that you people volunteer. The people here don't understand that. They think you are so rich that you can give away your time. Make them pay for your advice, like they pay for mine, then they will take it seriously. It also gives them the decision whether they want to have me here or not and makes me produce too."

In Malaysia, a long-time ago, before Malaysia became an eastern dynamo, well-intentioned Canadian physicians working there saw a problem. The intravenous tubing being used in a hospital was made of red rubber and they feared pyrogenic reactions, although no one had ever seen one. They discarded the rubber tubing, substituting plastic tubing instead. They proudly showed everyone how superior these were. They were sterile, single use and you could see air bubbles in the tube. The Canadians made a mistake. They assumed the local physicians would demand plastic intravenous tubes after they left and assumed they would be supplied. They were wrong. The team left and then there were no plastic tubes and no red rubber tubes. What should they have done? You decide.

People of western culture are sometimes guilty of trying to do too much with not enough thought. Some nongovernmental agencies have stopped supporting medical teams which purely treat the sick, preferring to seek a wider return on the donor dollar by clean water programs and feeding. This is their right, but donors should also support programs which treat the sick, operate on the maimed and the war-injured and give simply because people need help.

If we spent a billion dollars a year on student exchanges, international camping, or travel for all students, I think it would be a great investment. That way our younger generation would know people around the world and our ideas about them or us might change. We are all the same.

John R Taylor 